\title{
Quimera metálica Vida e artifício na cena contemporânea
}

\author{
Arthur Eduardo Araújo Belloni
}

Em seu artigo "Performance and theatricality: the subject demystified", Josette Féral, referindo-se à performance, reconhece a "manipulação do corpo" como uma de suas caracteristicas principais. De acordo com a pesquisadora, a cena performativa se destina a ser uma realização física e, nela, o performer dialoga com o seu próprio corpo como se este fosse um objeto estranho, lidando com ele de maneira distanciada, assim como, por exemplo, o pintor trabalha com a tela. Nesse sentido, ele o explora das mais diversas maneiras, dividindo-o, manipulando-o, remontando-o, pintando-o, congelando-o, movendo-o, cortando-o, isolando-o; o que, no ambiente cênico, pode ser sugerido, dentre outras possibilidades, por meio da utilização de várias mídias - câmeras, lentes teleobjetivas, telas de vídeo, televisões -, de modo a esculpir espaços físicos que criam espaços imaginários.

Em meio a tais operações, o corpo em pedaços mantendo uma certa unicidade a despeito de sua fragmentação - passa a ser percebido como um locus do desejo, propício a deslocamentos e disrupções; um corpo sobre o qual o performer atua no sentido de tentar libertálo de quaisquer formas de repressão que eventualmente o habitem, ainda que a custo de uma grande violência. Diante desse teatro da crueldade, o espectador passa à condição de participante numa espécie de ritual que combina todas as formas possiveis de transgressão: sexual e física, reais e encenadas. Esse ritual tenta, por sua vez, explorar a face oculta do que faz do performer um sujeito unificado. Conforme nos lembra Féral (1997), a dissolução do sujeito, nestes termos, se dá não por mero espalhamento ou loucura, mas pela via da pulsão de morte sugestionada por um completo "lesionismo" atrelado à experiência promovida pela exposição de corpos feridos, desmembrados, mutilados e cortados.

Além disso, a fragmentação do corpo se dá não para que ele seja negado, mas antes para que seja trazido de volta à vida por meio de cada uma das partes que o compõem. Nesse sentido, a performance acaba por desintegrar, e desmistificar o sujeito no palco, na medida em que ele é simultaneamente "explodido" em partesobjetos (personagens no teatro clássico, partes-objeto na performance) e "condensado" em cada uma dessas mesmas partes que, isoladas e ampliadas, se tornam entidades independentes, podendo ser reinventadas, multiplicadas e eliminadas se necessário, por meio de gestos que permitem ao performer estudar/apresentar os seus funcionamentos e mecanismos in vitro.

Por sua vez, Lehmann (2007), em seu estudo sobre o teatro pós-dramático, também se refere à divisão do corpo e seus desdobramentos na cena contemporânea, enfatizando principalmente aspectos relacionados à cisão entre locus agendie locus parlandie o consequente abalo da percepção na cena da persona unitária - enquanto sujeito autônomo, dono de sua voz. Esse tipo de separação entre voz e corpo, movimento e fala já era praticado no âmbito das composições cênicas desenvolvidas por simbolistas no final do século XIX, como no drama lírico La gardienne [A guardiã, 1894] de Henri de Régnier, no qual o poema era dito por atores situados no fosso da orquestra - logo invisíveis ao público - numa ação que ocorria paralelamente à pantomima realizada por outros atores localizados no palco, atrás de uma cortina de tule.

Ao se promover, de forma inaugural, esse corte entre a palavra e o acontecimento cênico, a cena simbolista afastava-se da concepção das dramatis personae enquanto figuras determinadas e encerradas em si mesmas. A despeito disso, "essa composição do modelo dramático só poderia se justificar completamente se houvesse uma consequente renúncia à ilusão de uma realidade reproduzida, o que só ocorreria mais tarde, na forma teatral pós-dramática" (Lehmann 2007: 99). Em meio às paisagens sonoras contemporâneas, nas quais vozes destituidas de corpos, muitas vezes em off, chocam-se contra outras vozes (ao vivo), não se sabe mais ao certo
Arthur Eduardo A. Belloni, com experiência na área das Artes (em Teatro Performativo), é Mestre e Doutor em Artes (Área de concentração Artes Cênicas) pela Escola de Comunicações e Artes da Universidade de São Paulo (USP), e Bachare em Artes Cênicas (habilitação em Direção Teatral) pela mesma instituição. É docente do Depto. de Artes Cênicas do Centro de Artes e Letras (CAL) da Universidade Federal de Santa Maria (UFSM) e integra o Grupo de Investigação do Desempenho Espetacular (GIDE) Atualmente, desenvolve projeto de pósdoutoramento no âmbito da Universidade do Minho (PT). 


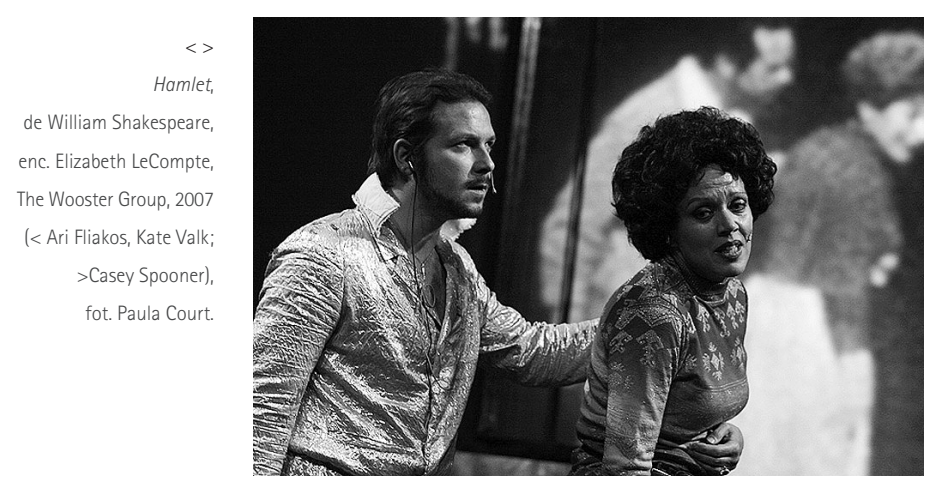

quem está falando. "Divisam-se os lábios que se movimentam, associa-se a voz com a imagem, junta-se o que está partido, perde-se de novo a conexão" (ibid: 260). A partir deste jogo friccional entre corpo e voz, em que a imagem passa a ser remodelada por mecanismos de sonoridade, partículas elétricas, palavras e trilhas, forjase todo um campo de atuação estética teatral eletrônica que abarca procedimentos composicionais tais como a dobragem e o playback, dentre outros.

Aspectos dessa "poética disjuntiva", como se pode notar, ultrapassam a esfera da mera manipulação corporal. Féral (1997), no texto supracitado, aponta para uma segunda caracteristica da performance que está relacionada à manipulação espacial. De acordo com a pesquisadora, ao jogar com o espaço performativo como se ele fosse um objeto, o performer o transforma em uma espécie de máquina que age sobre os órgãos dos sentidos. Assim sendo, ele recorta-o, explora-o, atravessa-o, num tipo de "travessia" sem paragem que jamais se cristaliza numa determinada forma, de modo a esculpir espaços imaginários e reais por meio dos deslocamentos e variações que operam no topos performativo (os espaços podem ser gerados, por exemplo, a partir da imagem de partes do próprio corpo do performer ampliadas ao infinito, ou ainda a partir de amplos espaços naturais que o performer reduz à dimensão de objetos manipuláveis). Da mesma maneira que o corpo, o espaço torna-se, nesse sentido, existencial, à medida que não se limita mais a um determinado lugar ou um cenário. Ele passa a ser parte da performance até o ponto em que não pode mais ser distinguido dela.

Tanto no processo de explosão/condensação citado por Féral (1997), como no "'agenciamento' maquinal complexo" (Lehmann 2007: 259) que se estabelece entre as partes-objeto no ambiente cênico, talvez seja possive observar reflexos da noção de corpo sem órgãos nos termos sugeridos por Gilles Deleuze e Félix Guattari no texto Mil platôs: Capitalismo e esquizofrenia (1999). De

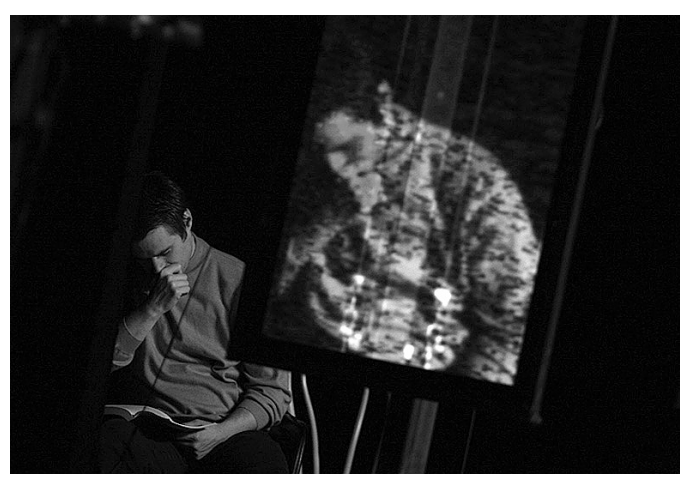

acordo com a concepção dos dois filósofos, o corpo sem órgãos (CsO) não se opõe aos órgãos, mas antes, à "organização orgânica dos órgãos" denominada organismo. Este último, por sua vez, não seria o corpo, mas antes um fenômeno de acumulação, sedimentação, decantação que, de forma dominante e hierarquizada, impõe àquele (CsO) determinadas funções, sintaxes, com vistas à sua domesticação gramatical e, a partir dela, a efetivação de um campo de trabalho pleno de utilidades.

Ao contrário disso, no corpo sem órgãos os órgãos passam à condição de intensidades, fluxos, distribuindose independentemente da forma do organismo que se torna, por sua vez, totalmente contingente; contudo, isso não implica o despedaçamento do corpo em relação a uma unidade perdida, ainda que haja, na variedade de agenciamentos possiveis desencadeada pelo corpo sem órgãos, arranjos e cruzamentos impositivamente "monstruosos" que acabam por promover uma "pura multiplicidade de imanência, da qual um pedaço pode ser chinês, um outro americano, um outro medieval, um outro pequeno-perverso" (Deleuze / Guattari 1999: 19), num jogo de hibridismos e combinações desterritorializadas que, desarticulando pontos de subjetivação e significância, liberam o corpo das estruturas fixas ao mesmo tempo em que o lançam às experimentações. Afinal, "[p]or que não caminhar com a cabeça, cantar com o sinus, ver com a pele, respirar com o ventre?" (ibid. : 11).

\section{Corpos e artefatos}

Assim como Féral, o teórico Martin Puchner, num trecho de seu estudo Stage Fright: Modernism, Anti-Theatricality and Drama (2002), ao discorrer sobre os aspectos do "teatro multimídia" contemporâneo, também comenta que o uso das novas tecnologias no âmbito da cena atual propicia vários tipos de manipulação: as vozes e os corpos dos atores são apartados e distanciados uns dos outros; monitores de video duplicam e ocultam, ainda que 

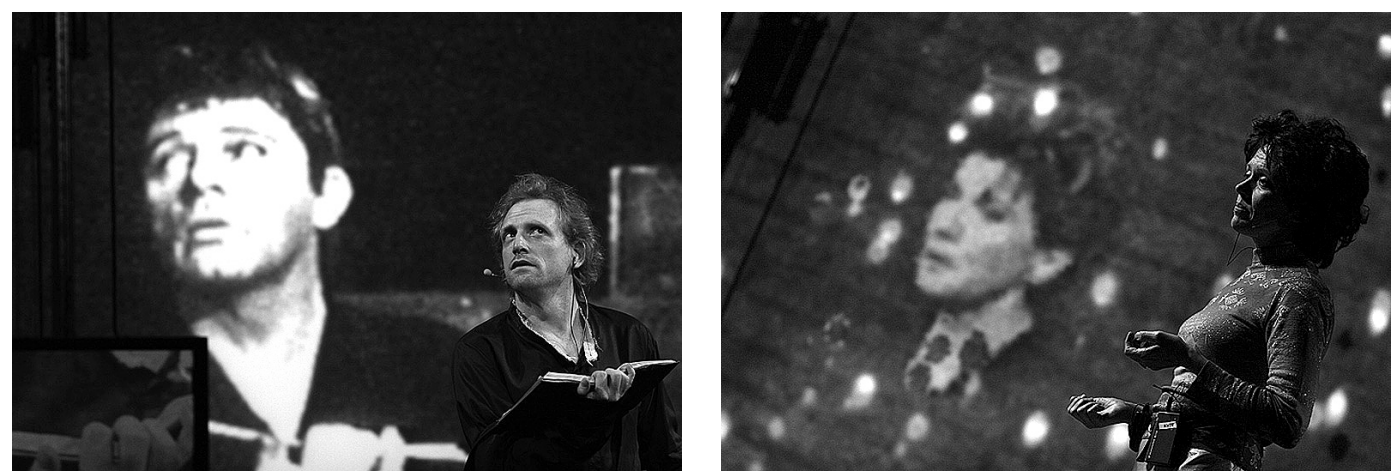

$<>$
Hamlet

de William Shakespeare,

enc. Elizabeth LeCompte, The Wooster Group, 2007

(< Scott Shepherd;

$>$ Kate Valk),

fot. Paula Court.
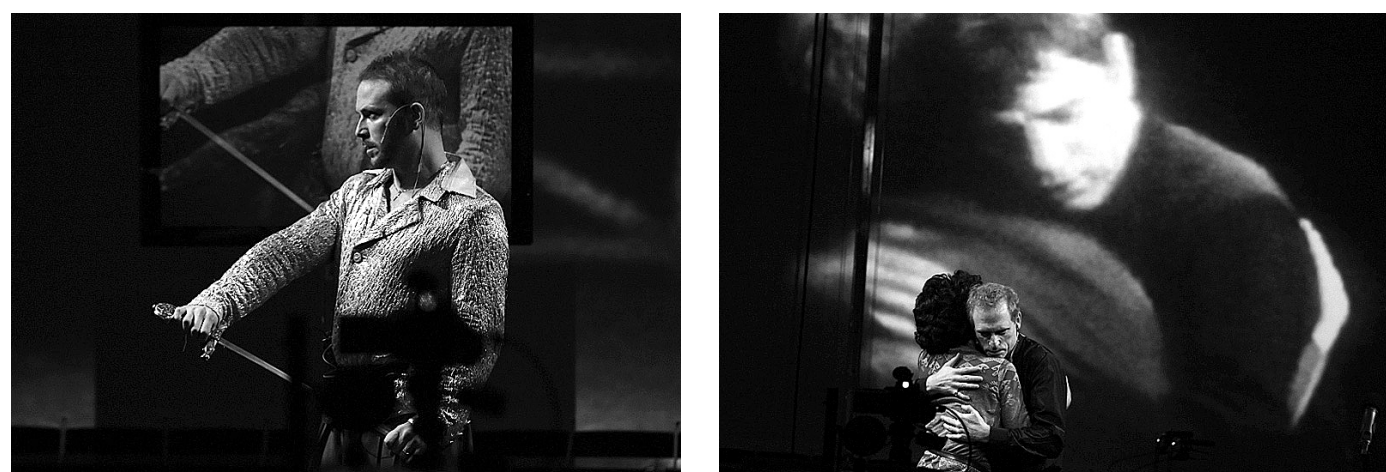

$<>$

Hamlet,

de William Shakespeare,

enc. Elizabeth LeCompte, The Wooster Group, 2007 (<Ari Fliakos:

$>$ Kate Valk e Scott Shepherd), fot. Mihaela Marin.

parcialmente, estes corpos, substituindo-os pela manifestação imaterial de suas imagens afastadas temporal e espacialmente, gerando uma situação que propicia o estabelecimento de "diálogos" entre o ator e o seu duplo.

Outro aspecto comum a este tipo de cena midiática consiste no uso frequente de vozes e gestos de outrem que não os do performer envolvido diretamente na cena. Puchner (ibid.) cita o Wooster Group como exemplo de companhia teatral que faz uso da tecnologia de maneira a subverter a ideia essencialista da presença viva dos atores no palco. 0 autor nos lembra que todos esses aspectos relacionados a essas formas hodiernas de midiatização da cena remetem à análise feita por Philip Auslander que, ampliando e modificando a tese de Walter Benjamin sobre a destruição da aura ocasionada pela difusão dos meios técnicos de reprodução, argumenta que, em meio ao quadro da cena contemporânea, nós não podemos mais definir o teatro e a performance a partir de conceito associado à pura, viva e incontestável presença humana do ator no palco, uma vez que muitas formas do teatro contemporâneo e da performance promovem uma mistura de midiatização e presentificação.

De acordo com o ponto de vista de Puchner (ibid.), estas transformações trouxeram profundas implicações para os rumos da antiteatralidade modernista, uma vez que, frente ao palco fraturado por monitores e pela tecnologia sonora, o material mimético deixa de comandar a cena, tornando obsoletos os apelos modernistas refratários ao teatro "mimético", "pessoal", "aurático": Para muito além da divisão mimesis/diegesis de Yeats ou das estruturações dialéticas de Brecht, a "presença viva" (que tanto incomodava Gertrude Stein, cabe lembrar também) foi radicalmente desmantelada. No palco midiatizado, a separação dos elementos desdobrou-se de forma cruel e assombrosa. Para Puchner (ibid.), o teatro midiático, ao se valer de instrumentais tecnológicos de reprodução e se afastar do modelo de teatro "aurático", dá continuidade ao teatro diegético modernista de natureza antiteatral.

Esse antiteatralismo, contudo, em última instância como nos lembra o próprio Puchner, acaba por dar lugar à manifestação de uma outra forma de teatralidade. E, de fato, não por acaso, o teatro midiático costuma ser frequentemente associado à "obra de arte total" wagneriana, paradigma-mor, de acordo com o próprio Puchner, da teatralidade. Alain Badiou, por exemplo, em conversa com Elie During (Badiou / During 2007), faz ressaltar exatamente certos aspectos relacionados a essa forma de teatralidade decorrente do uso de tecnologia pelo teatro no contexto da democracia tecnicizada. Partindo da afirmação de que o teatro encerra sempre uma reflexão pública sobre o laço e o não-laço entre o artifício e a vida, Badiou aponta quatro maneiras de lidar com esta questão, quais sejam: dissimular o artificio sob a norma do natural; mostrar o artificio de modo a criticar as formas recebidas do natural; fazer valer que toda a "natureza" é ela própria uma construção artificial; ou ainda, "naturalizar" o artifício.

Esse último procedimento, de acordo com Badiou, é o mais experimentado na atualidade, uma vez que, frente à força portentosa ostentada pelos aparatos tecnológicos fora e dentro do ambiente cênico, surge a tentação de teatralizá-la, o que se estabelece por meio de um jogo que promove a mostração do poder desses artefatos, ao mesmo tempo que os derrota pela absorção vital; "uma espécie de equalização monstruosa do órgão vivo e da quimera metálica propõe um novo tipo de equilibrio instável entre o artifício e a vida (...) isso orienta a fórmula 'não há senão corpos e linguagens' para uma variante: não há senão corpos e artefatos" (ibid:: 25). Deste modo, o fato de a cena multimídia ter rompido com a celebração do caráter imediato do corpo e apelado às mais variadas formas de artifício - máquinas, dispositivos de vídeo, softwares, ambientes da internet, próteses tecnológicas -, de acordo com Badiou, é reflexo não de uma concepção teatral que pressupõe total controle da cena (por parte 


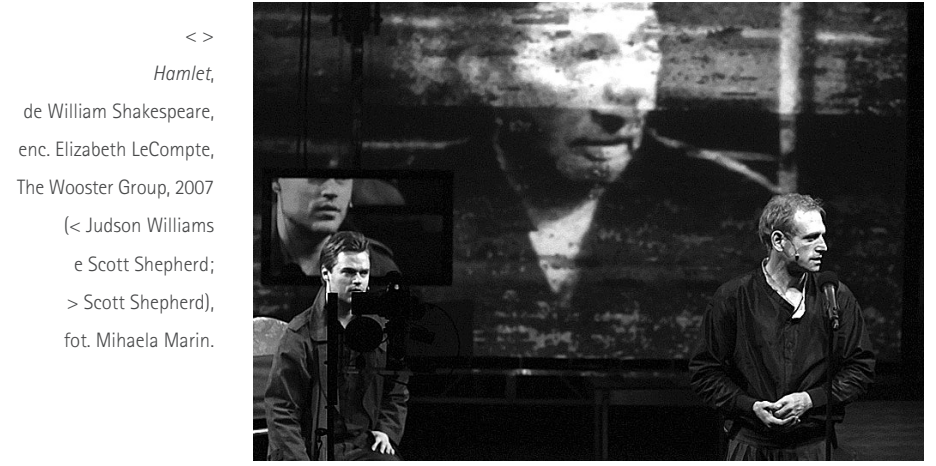

do encenador, ou de quem quer que seja), mas antes, de uma naturalização do artifício cujo efeito é, do seu ponto de vista, teatral.

Numa abordagem aproximada, Hans-Thies Lehmann (2007), ao chamar a atenção para o modo como a tecnologia das mídias - associada ao mecânico, à reprodução e à reprodutibilidade - é teatralizada na cena multimídia contemporânea, afirma que, no topos high tech dessa modalidade teatral, ocorre uma intensificação e uma desconstrução do teatro nos mais variados níveis: "o teatro 'vivo' é posto em suspensão e passa a ser uma ilusão, um efeito de uma máquina de efeitos. Por outro lado, experimenta-se na atmosfera intensa e vital do trabalho uma tendência inversa: a tecnologia das mídias é teatralizada" (ibid:: 384). Para Lehmann, o mecânico, a reprodução e a reprodutibilidade, antes de negar, reafirmam a teatralidade à medida que servem à atualidade do teatro e, consequentemente, à vida. Nesse sentido, ele questiona se os recursos de multimídia, estando relacionados às técnicas de "ilusionismo", representariam uma ruptura na história do teatro - enquanto medium de uma determinada tecnologia da "representação" -, ou se "a incerteza sobre o status de realidade do que é representado, ou seja, mostrado como ilusão, significam apenas uma nova modalidade do maquinário da ilusão que o teatro já conhecia" (ibid:: 374)

Deve-se ressaltar, no entanto, que o "ilusionismo" próprio ao chamado teatro performativo contemporâneo não envolve necessariamente a ideia de ficção. Sobre esse aspecto, cabe lembrar, o que sustenta o próprio Lehmann (2007) quando observa que a chamada "ilusão" pode se manifestar através de diferentes vias: do "Espanto" diante dos possiveis efeitos de realidade (aspecto de magia); da "Identificação" com a intensidade sensorial dos atores e das cenas teatrais, das formas de movimento dançantes e das sugestões verbais (aspecto do Eros, claro ou escuro), ou, ainda, da "Projeção" de conteúdo de uma experiência de mundo própria sobre os modelos teatrais representados, associada aos mentais de "preencher e esvaziar" e à empatia com os personagens (ibid: 180).

Como faz destacar o teórico do teatro, somente o último aspecto diz respeito à ficcionalidade no sentido estrito do termo, o que explica o fato de que, a despeito do recuo, e até mesmo do desaparecimento da ficção, não se elimina a experiência da "passagem", da "transportação", do "rapto" para o reino da aparência, o qual, por sua vez, costuma ser, de forma apressada, confundido com a ilusão. Tanto a camada relacionada à magia, como aquela relacionada ao Eros permanecem, nesse sentido, passiveis de manifestação,

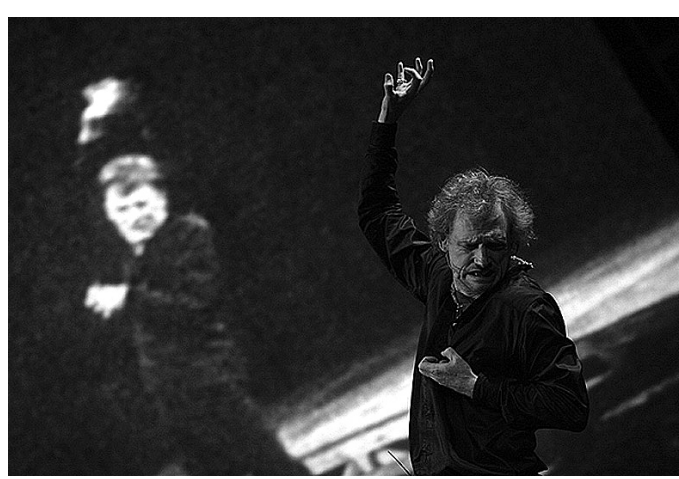

independentemente de quaisquer planos de ficção. Em última instância, seria possivel dizer que essa observação de Lehmann nos sugere um princípio de resposta a uma questão colocada, recentemente, por Féral (2008), a saber o teatro se distanciou da representação. Terá ele se distanciado, de fato, da teatralidade?

\section{Referências bibliográficas}

BADIOU, Alain / DURING, Elie (2007), "Um teatro da operação: uma conversa entre Alain Badiou e Elie During",in Um teatro sem teatro, catálogo da exposição organizada pelo Museu d'Art Contemporani de Barcelona e co-produzida com o Museu Colecção Berardo - Arte Moderna e Contemporânea de Lisboa.

BELLONI, Arthur E. A. (2011), Teatro menos teatro, São Paulo, ECA/USP (tese de doutoramento).

COHEN, Renato (2003), "Rito, tecnologia e novas mediações na cena contemporânea brasileira", in Sala Preta, São Paulo, ECA/USP, n. 3 , pp. 117-124

COHEN, Renato et al. (2006), Dicionário do teatro brasileiro - temas, formas e conceitos, São Paulo, SescSP/Perspectiva (verbete multimidia).

COLWELL, Chauncey P. (1997), "Deleuze \&t Foucault: Series, Event, Genealogy", in Theory \& Event, Volume 1, Issue 2, The John Hopkins University Press.

DELEUZE, Gilles / GUATTARI, Félix (1999), Mil platôs. Capitalismo e esquizofrenia, Vol. 3. São Paulo, Editora 34.

DELEUZE, Gilles (2010) Sobre o teatro, Rio de Janeiro, Jorge Zahar Editor Ltda.

FÉRAL, Josette (1997), "Performance and Theatricality: The Subject Demystified", in Thimothy Murray, Mimeses, Masochism, Mime, the Politics of Theatricality in Contemporary French Thought, Ann Arbor The University of Michigan Press, 1997, pp 289-300

-- (2002), "Foreword", in Substance, 1998/99, vol. 31, n. 2 e 3, pp. 3-12

-- (2008), Por uma poética da performatividade: 0 teatro performativo in Sala Preta, São Paulo, ECA/USP, Volume 8, pp. 197-210.

LEHMANN, Hans-Thies (2007), Teatro pós-dramático, São Paulo, Cosac \& Naify.

LYOTARD, Jean-François (1997), "The Tooth, the Palm", in in Thimothy Murray, Mimeses, Masochism, Mime, the Politics of Theatricality in Contemporary French Thought, Ann Arbor, The University of Michigan Press, pp. 282-288.

-- (1997), O inumano, Lisboa, Editorial Estampa.

PAVIS, Patrice (2010), A encenação contemporânea, trad. Nanci Fernandes, São Paulo, Perspectiva.

PUCHNER, Martin (2002), Stage Fright: Modernism, Anti-theatricality and Drama, Baltimore e Londres, The Johns Hopkins University Press. 